\title{
SPEECH RECORDING IN STUTTERING THERAPY
}

\author{
ERICA STERN, B.A., Dip. Log.
}

South Africans generally, and school children in particular, have become increasingly radio-conscious within recent years. No doubt the advent of "Springbok Radio" has had a great deal to do with this. After school is over for the day, children enjoy listeningin to tales of adventure and travel, radio plays and dramatised broadcasts of stories, as well as a variety of other programmes.

Thus the pupil who is given the opportunity of making a recording of his speech is bound to win the admiration of his listeners when the recording is played back, since a tope (or wire) recorder is still a novelty, not being yet in everyday use.

However, if a stuttering pupil is to derive enjoyment and benefit from the use of the recorder, certain considerations should be borne in mind by the speech therapist.

Firstly, children who are asked to speak impromptu into the microphone of a record. ing instrument are likely to be more hesitont in their speech than is usually the case. This will become apparent when the recording is played back. Secondly, children are likely to be adversely affected upon hearing a recording of their own, non-fluent speech. The above points are illustrated by the case of Jimmy, mentioned by Prof. Wendell Johnson. (2)

It is the opinion of the writer, therefore, that a tape recorder should only be used with stuttering pupils when it is possible to record a fluent sample of their speech, or at least speech that is decidedly more fluent than their usual way of speaking. Hearing such a recording of their speech will give a feeling of encouragement and satisfortion to the stutterers.

\section{VARIOUंS RECORDINGS BY UNIVERSITY STUDENTS.}

Lucile Cypreansen ${ }^{(1)}$ reports interesting experimentation in the making of different types of recordings with a group of 14 University of Nebraska men students (all of whom were stutterers), between the ages of 18 and 23 years, as part of the speech-therapy programme during the first course of fifteen meetings.

Speech recordings were made from the 11 th to 14 th meetings.

\section{1 th MEETING.}

"Each student tried the 'two-room' tech- nique, speaking extemporaneously and reading aloud while shut off in a room by himself. In a connecting room, closed off by a door, the supervisor made electrical tronscriptions of what was being said. The microphone of the recorder was placed in the room with the speaker. Interesting results were noted. The speaker knew the recording was going on, but he did not know just when his speech was being recorded. Speech patterns on the records showed much improvement over speech patterns used in daily speech. The subjects were pleased and encouraged by the results of the recordings.

12th MEETING.

"A type of 'psychodrama' was tried. The students were given a hypothetical incident to dramatise informally without previous practice.

"Two students were placed in the room with the microphone. They proceeded to carry on the dramatisation of the incident. There was very little stuttering noticed in this type of dramatisation. The supervisor and the rest of the group in the other room could hear over the connecting amplification system all that was said. Parts of the dramatisations were recorded. Later the recordings were played back to the group. The subjects were free and easy in this project and appeared to enjoy the performances thoroughly...

"An assignment was made for the next meeting. Each student was to bring a threeor four-minute selection that he would like to read to someone else.

\section{3th MEETTNG.}

"The selections assigned for oral reading were practised on the wire recorder. Two students worked together on one recorder, recording and listening, and offering suggestions to each other...

\section{4th MEETING.}

"Electrical transcriptions were made of readings of the material which had been previously assigned and practised on the wire recorder. The members of the group were allowed to take their records home to play for their families and friends. They were then returned and filed in the individual clinic folders."

Cypreansen reports that by the next (15th) meeting (which was the end of the first 
course), "most of the members of the group appeared to have gained greater confidence in speaking situations. . . and several of the students appeared to show definite improvement in speaking habits."

At the opening of the following term the students decided to continue with their group work. Additional projects were undertaken and "the making of the recordings was to be continued."

\section{RECORDED PROGRAMMES BY PRIMARY SCHOOL CHILDREN.}

In the larger centres of the Cape Province, where classes for speech defective school children are carried on under the Cape Education Department, the members of the itinerant staff have at their disposal a tape recorder, and a couple of reels for the use of each staff member. Up to the present time, however, the writer has had only limited experience in the use of the tape recorder for dramatisation with stuttering pupils.

The tape recorder offers some advantages over the presentation of "live" plays.

(a) It is preferable to use the recorder in cases where the speech of the stuttering pupil has begun to show an improvement, but where the therapist fears that there is $\approx$ possibility of the pupil's speech breaking down in front of an audience.

(b) There is bound to be an improvement in the speech of the pupils after a number of rehearsals. "The adaptation effect (the tendency for stuttering to decrease with successive readings of the same passages) was first reported in 1937 by Johnson and Knott, and it has since been repeatedly confirmed in experimental studies... Johnson and Innes found that in five successive readings of a short passage there was an average reduction in frequency of stuttering of approximately 50 per cent."

(c) If desired, the therapist can make more than one recording of the same programme, and select the best (or better one) to be played back. (The others can be erased and that portion of the reel used again).

(d) Certain radio plays and broadcast programmes can be recorded easily which would be difficult to present on a stage.
The recordings were made by 13 boys, whose speech was marked by stuttering in varying degrees, from Standards 1 to 5 inclusive in primary schools in Cape Town. These pupils were receiving treatment in three groups of three each, and two groups, each consisting of two pupils. The four latter pupils were combined into one group for the purpose of the recording. The pupils were told that they could make a recording to be played back to their classes at the end of the second quarter (in June).

One of the groups (consisting of three Standard 5 pupils), preferred to write their own programme. Thus "Tintown Calling," (a skit on "Snoektown Calling"), came into being. It incorporated the pupils' own ideas, with some help from the therapist. The pupils were particularly keen on sound effects, and brought tins, a cane and a knobkerrie for the purpose.

For use with stuttering pupils (whom the writer prefers to treat in small groups of two or three), very suitable, graded plays are to be found in Harrap's "New Dramatic Readers," Books 1-4, and in the recently published series of five books entitled "Prettige Praatstories" (Nasionale Boekhandel). The three plcys to be recorded by the groups were chosen from the above books by those taking part.

Each pupil was asked which part he would like to take. If only one pupil chose a particular part, he was given that part in the play. Otherwise lots were drawn for the parts. Thus no pupil felt that any foryouritism had been shown, and all were afterwards perfectly satisfied with their parts.

A typewritten script was given to each pupil to enable him to rehearse the play at home with his parents, brothers and sisters.

The class teachers concerned showed keen interest in the idea and were eager to make the necessary arrangements for the performances (i.e., the playing of the recordings to the different classes).

All the performances achieved great success. The listeners showed their appreciation by requesting. "Can't we hear it agcrin," and it was obvious that the stutterers, who were able to observe the reactions of the cudience, derived great enjoyment from hearing the recordings they had made. 
Since rehearsals for the recordings were held for a comparatively short period of time, (owing to the illness of the therapist), and as this method was only used as part of the treatment that the pupils received, it is difficult to estimate the degree of improvement that the use of this technique brought about in the speech of the pupils (if at all), and for how long it would have lasted.

The writer would be interested to know of the results obtained by other speech therapists using speech recording in stuttering therapy.

\section{BIBLIOGRAPHY.}

1. Cypreconsen, Lucile, "GROUP THERAPY FOR ADULT STUTTERERS," The Journal of Speech and Hearing Disorders, December, 1948, pages 313-319,

2. Johnson, Wendell, "SPEECH HANDICAPPED SCHOOL CHILDREN," Harper and Brothers, New York, 1948. Appendix.

3. Johnson, Darley and Spriestersbach, "DIAGNOSTIC MANUAL IN SPEECH CORRECTION" Harper and Brothers, New York, 1952, page 122.
P.O. Box 10482

Telephones 22-4656

23-9432

\section{ABE ETKIND (PTY.) LTD.}

WHOLESAIE MERCHANTS.

First Floor, LINCOLN HOUSE,

57 Pritchard Street,

Johannesburg.

WORLD'S FINEST HEARING-ADS.

3 TRANSISTOR From $£ 29 / 15 / 0$

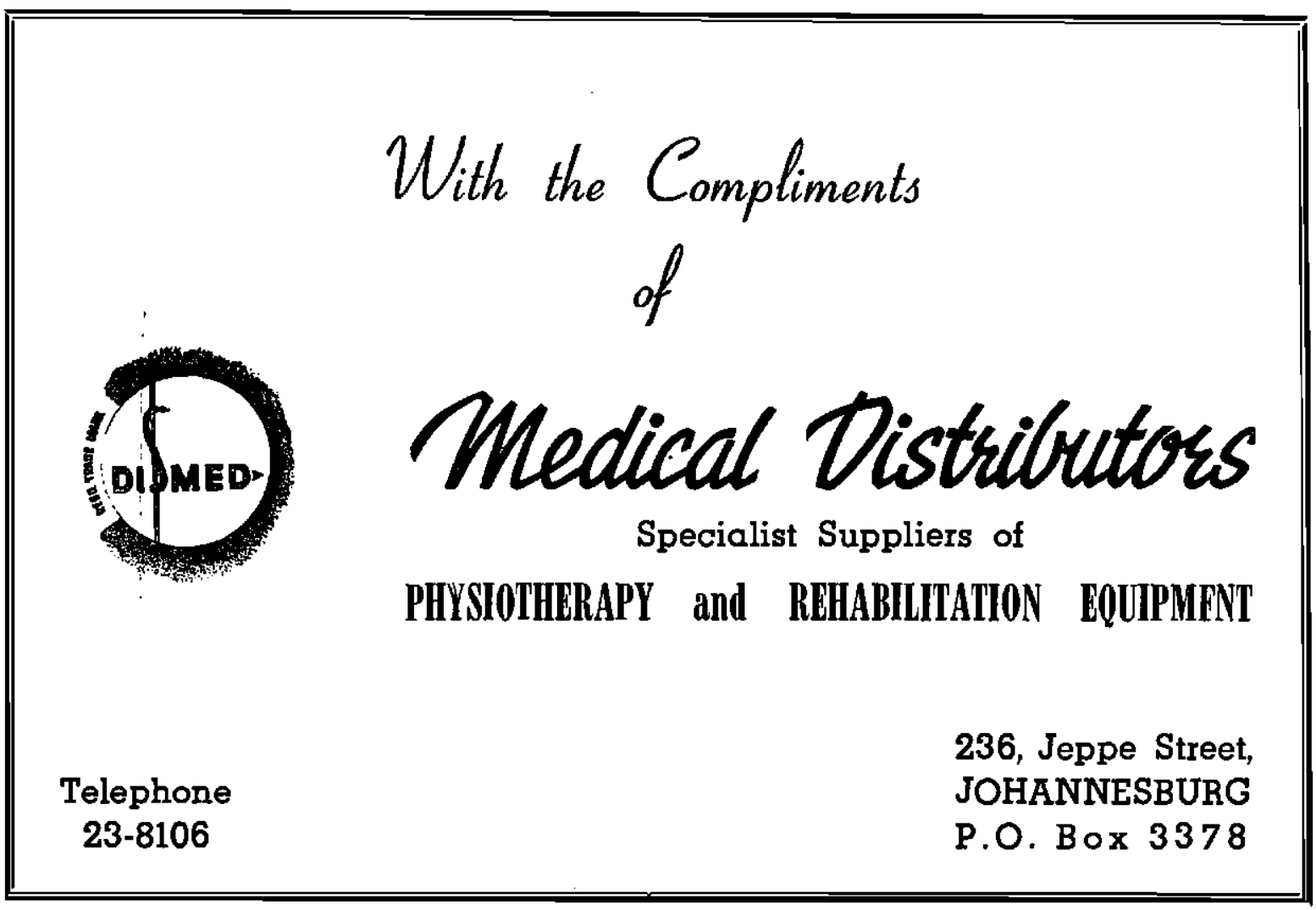

